\title{
A cultural inquiry into ambidexterity in supervisor-subordinate relationship
}

\begin{abstract}
Guanxi is a key construct in Chinese management and organization scholarship, and has been widely treated as a relational concept. However, it is necessary to gain a nuanced and contextualized understanding of Guanxi to examine its cultural antecedents by resorting to traditional Chinese cultures. We draw upon the emerging literature on ambidexterity and HRM to examine Guanxi in the context of superior-subordinate relationship and conceptualize ambidextrous Guanxi as possessing two orientations: relational and meritbased. To investigate ambidextrous Guanxi in the context of superior-subordinate relationship, we perform in-depth, qualitative narrative interviews with managers in Chinese state-owned enterprises (SOEs). Our results reveal three dimensions: loyalty, dependence upon supervisor, and work priority by which ambidextrous Guanxi enables, facilitates, and accommodates the tension between individual career advancement and commitment to the organization. From a cultural inquiry perspective, we argue that Confucianism and Legalism, as cultural antecedents of ambidextrous Guanxi, shed light on its contemporary managerial implications. Our findings suggest that Guanxi can be considered as a strategic HR asset and enhance performance outcomes both at the individual level (career advancement) and the organizational level (commitment to the organization).
\end{abstract}

Keywords: culture, Chinese philosophies, ambidexterity, Guanxi, supervisor-subordinate, career. 


\section{Introduction}

The notion of Guanxi is an indigenous management concept, which, in conjunction with market transition (Nee, 1992) and network capitalism (Boisot \& Child, 1996), has been used in China to contextualize organization research in the last three decades (Jia, Yuo \& Du, 2012). The present study debates and empirically tests the prevalence of Guanxi and its role in Chinese organizations and within society at large. For example, Chinese firms can develop Guanxi as a strategic mechanism to overcome competitive and resource disadvantages (Park \& Luo, 2001). Leadership styles and Guanxi networks affect Chinese employees' retention in mergers and acquisitions (Zhang et al., 2015a). Guanxi can be leveraged to acquire resources for young technology ventures and to foster innovation (Liu, Woywode, \& Xing, 2012a).

Received wisdom overwhelmingly treats Guanxi as a relational concept (Xin \& Pearce, 1996). Arguably, the relational orientation, with the emphasis on "heart" (affect-based) rather than "head" (cognition-based) differentiates Guanxi from social networks in Western contexts (Chua, Morris, \& Ingram, 2009). Guanxi appears to exist beyond the relational rhetoric, and can be deployed from a transaction-oriented perspective, as, for example, in the coexistence of transaction and relational marketing practices in China (Styles \& Ambler, 2003). The transaction-oriented perspective largely reconciles the market-based transaction approach with emphasis on arm-length interactions. It is necessary, therefore, to gain a nuanced and contextualized understanding of Guanxi in Chinese organizations. The present paper aims to explain the construct of Guanxi by drawing on the emerging literature on ambidexterity (Junni, Sarala, Taras, \& Tarba, 2013; Junni, Sarala, Tarba, Liu, \& Cooper, 2015; Luo \& Rui, 2009) in the context of supervisor-subordinate relationship. 
Ambidexterity has emerged as a vibrant academic field in organization and management scholarship ( O’Reilly, Bruce, \& Tushman, 2009; O'Reilly \& Tushman, 2004; 2013; Smith \& Tushman, 2005). Recently, scholars started to examine ambidexterity from an HRM perspective, for example, ambidextrous learning and human resource practices in Spain (Prieto \& Santana, 2012); high performance work systems and organizational ambidexterity (Patel, Messersmith, \& Lepak, 2013); individual micro-level HR and ambidexterity (Stokes et al., 2015b); leadership (Carmeli \& Halevi, 2009; Mihalache, Jansen, Van Den Bosch, \& Volberda, 2014); the effect of the CEO and of the top management team (Cao, Simsek, \& Zhang, 2010; Lubatkin, Simsek, Ling, \& Veiga, 2006); strategies for leveraging teams in order to attain organizational effectiveness (Chermack, Bodwell, \& Glick, 2010); and ambidextrous incentive schemes on employee performance (Ahammad, Lee, Malul, \& Shoham, 2015). But research is still lacking on ambidexterity beyond the organizational level (Raisch \& Birkinshaw, 2008; Turner, Swart, \& Maylor, 2013), although a few recent studies have started to pursue this line of inquiry at the business unit level (Chebbi, Yahiaoui, Vrontis, \& Thrassou, 2015) and at the individual level (Rogan \& Mors, 2014; Stokes et al., 2015b).

There is scant research using ambidexterity perspectives to examine inter-personal relationships, which are a key topic in HRM. A study by Halevi, Carmeli, and Brueller (2015) explored the effect of top management team (TMT) processes on organizational ambidexterity, pointing out the importance of environmental dynamism as a boundary condition for the effectiveness of TMTs in promoting balance between exploratory and exploitative learning. Their findings indicate that behavioral integration by the TMT helps build ambidexterity, and that the influence of TMT behavioral integration on ambidexterity is stronger when the task environment is characterized by a high level of dynamism. Based on multi-source, multi-level data obtained from 2,887 employees and 536 managers of 58 banks, Chang (2015) revealed that firm-level high-performance work systems (HPWS) have been positively related to unitlevel employee human capital, which partially mediated the relationship between firm-level 
HPWS and unit organizational ambidexterity, whereas firm-level social climate moderated the effect of firm-level HPWS on unit organizational ambidexterity through unit-level employee human capital. A study by Kostopoulos, Bozionelos, and Syrigos (2015), based on a sample of 148 business units from 58 US Fortune 500 firms, proposed a cross-level model examining the effects of intellectual capital facets (i.e., human, social, and organizational capital) on unit ambidexterity, suggesting that organizational-level high-performance human resource (HPHR) practices significantly shape these effects as well as the unit ambidexterity - unit performance relationship. Unit human and social capital exerts a positive effect on unit ambidexterity, whereas organizational capital has been found to be negatively associated with unit ambidexterity, and organizational HPHR practices enhance the former and reduce the latter of these unit-level effects. The authors also showed that the relationship between ambidexterity and unit performance turns out to be stronger in organizations in which HPHR practices are more prominent (Kostopoulos, Bozionelos, \& Syrigos, 2015). Our research fills this important gap of inter-personal relationships by investigating the supervisor-subordinate relationship in Chinese organizations.

The supervisor-subordinate relationship has received wide attention in the HRM literature. With reference to China, several studies have articulated the importance of supervisorsubordinate relationship and of its relation to Guanxi, for example, how supervisorsubordinate Guanxi affects supervisor's administrative decisions (Law, Wong, Wang, \& Wang, 2000), and how trust in the superior-subordinate relationship influences employees' intention to quit the workplace (Wong, Wong, \& Wong, 2010). Existing research on supervisor-subordinate relationship focuses largely on individual-level outcome and the mechanisms that may affect it. For example, political skills are positively related to career success and job satisfaction (Munyon, Summers, Thompson, \& Ferris, 2015). We argue that both individual- and organization-level outcomes are intertwined with the supervisorsubordinate relationship, so that an ambidexterity perspective of the supervisor-subordinate 
relationship may reconcile the tension between the different levels. We conceptualize the ambidextrous Guanxi as having two orientations: relation and merit-based, and investigate ambidextrous Guanxi empirically in the context of the superior-subordinate relationship in Chinese organizations.

We explore the supervisor-subordinate relationship in order to examine the influences of traditional culture on it in the context of Chinese state-owned enterprises (SOEs). To this end, we conducted in-depth interviews with 28 senior and middle managers from SOEs from five industry sectors: banking, construction, mining, telecommunications, and aerospace. In the present study, we resorted to the storytelling method to collect rich qualitative data from the informants. Storytelling has been shown to be a powerful research method for the investigation of complex topics in international HRM.

The present paper contributes to the emerging literature on ambidexterity and HRM by conceptualizing ambidextrous Guanxi. We explain the mechanisms by which ambidextrous Guanxi accommodates and enables the tension between individual-level outcome (career advancement) and organizational-level outcome (organizational performance). Our findings lend support to the argument that Guanxi can be considered a strategic HR asset and can enhance the performance of the organization. We argue that relation-based Guanxi directs managers' attention to building and maintaining relationships with supervisors, an achievement attributed to good relationships, whereas merit-based Guanxi focuses on the individual contribution and keeps the relationship with supervisors at arm's length. We underscore the importance of Chinese traditional culture and philosophy, as manifested in Confucianism and Legalism, and their contemporary implications for organization and management studies (Ma \& Tsui, 2015). Our study shows that Chinese traditional culture persists resiliently amid the contention and tension between relation- and merit-based Guanxi. Managers can build a variety of strategies based on traditional cultures to manage the 
superior-subordinate relationship. Chinese philosophy provides the fundamental principles that guide managers' behaviors in dealing with their supervisors, while using ambidextrous Guanxi.

We begin by reviewing the literature on ambidexterity and HRM, superior-subordinate relationship, ambidextrous Guanxi, and Chinese traditional culture. This forms the theoretical background of the article and provides the building blocks of our arguments. Next, we propose a conceptual framework for ambidextrous Guanxi in superior-subordinate relationships, and describe the research design and context. We continue by presenting the empirical findings and results, and conclude with a discussion of the implications of our results, the limitations of the study, and directions for future research.

\section{Theoretical background}

\section{The nexus between ambidexterity and HRM}

Ambidexterity, based on the influential concepts of "exploration" and "exploitation" (March, 1991), has received extensive scholarly attention in organization and management scholarship (O'Reilly \& Tushman, 2013). A recent meta-analytical review found a positive relationship between organizational ambidexterity and performance (Junni et al., 2013). But existing studies focus mainly on organization-level analysis (Turner et al., 2013). It has been suggested that construct clarity (Birkinshaw \& Gupta, 2013) and levels of analysis are promising paths for advancing ambidexterity research (Simsek, 2009). Although it is necessary to study ambidexterity beyond the organizational level, there has been little research on ambidexterity at the individual level of analysis. For example, Filippini, Güttel, and Nosella (2012) studied ambidextrous routines in knowledge management and identified initiatives that concurrently facilitate exploration and exploitation at the micro-level. They concluded that firms create a learning context that can be activated when necessary in ways 
that require either an exploratory or an exploitative mode. Huang and Kim (2013) investigated how a large Korean multinational company, LG Electronics, achieved structural ambidexterity within the HRM function through architectural innovation. The study stressed the need for continuously adjusting HRM practices to adapt to the ever-changing business environment. In the same vein, Good and Michel (2013) developed and tested hypotheses concerning the formative construct of individual ambidexterity based on the predictive validity of a laboratory study in which 181 undergraduate students participated in a real-time, dynamic computer simulation. Drawing on the organizational, psychological, and neuroscience literatures, the authors identified the cognitive abilities necessary to balance the conflicting demands of exploration and exploitation. Our study aims to fill this gap of interpersonal relationships by investigating individual behaviors within the organization from the perspective of ambidexterity.

Only a few studies to date have examined the relationship between HRM and ambidexterity, and the effect of this relationship on performance. For example, research on 215 small to medium-sized high-tech enterprises shows that high-performance work systems are positively related to organizational ambidexterity (Patel et al., 2013). Another study reveals that ex ante incentives (based on past performance) and ex post incentives (based on future performance) affect the productivity, motivation, and performance of employees at commercial banks (Ahammad et al., 2015). A study conducted from a network perspective shows that top managers' social networks inside and outside the firm can collectively provide dual knowledge benefits conducive to ambidexterity (Heavey, Simsek, \& Fox, 2015). Moving down the level of analysis, a study with a focus on the business-unit level explores the evolutionary process of a divisional multi-business-unit organization aimed at achieving divisionalized ambidexterity (Chebbi et al., 2015). From the perspective of critical management studies, one study uses the concept of micro-moment to illuminate the micro- 
dynamics of intra-organizational and individual behavior in delivering organizational ambidexterity (Stokes et al., 2015b).

There has been limited research based on the ambidexterity perspective investigating the key HRM topic of inter-personal relationships. We propose a nuanced understanding of ambidexterity, focused on inter-personal relationships. The inter-personal relationships may challenge the boundary conditions and assumptions of existing conceptualization of ambidexterity by providing a new empirical context (George, 2014). The concept of ambidexterity can shed light on the role of inter-personal relationships in HRM scholarship and practice, which is the source of the motivation for the present paper to investigate supervisor-subordinate relationship in Chinese organizations from the ambidexterity perspective.

\section{Supervisor-subordinate $(S-S)$ relationship and Guanxi}

The construct of leader-member exchange (LMX) has been widely used in leadership research to examine the antecedents and consequences of this relationship for both individual and organizational performance (Dulebohn, Bommer, Liden, Brouer, \& Ferris, 2012). As a Western concept, LMX reflects the quality of exchange between the supervisor and the subordinate. Within the context of Chinese organizations, Guanxi was incorporated into the LMX conceptualization. Within the S-S relationship, Guanxi was defined as a non-workrelated personal relationship between subordinate and supervisor through informal social interactions (Chen \& Tjosvold, 2006). Unlike LMX, which is a relationship usually restricted to the workplace, the cultivation of Guanxi in S-S involves more non-work than work-related activities (Zhang, Li, \& Harris, 2015b). Subordinates in Chinese organizations can work through informal channels to establish Guanxi with their supervisors, for example, through various social activities such as dinners, gift, and favors (Law et al., 2000). 
Research on Guanxi in S-S relationship generally addresses two issues: the strategic utility of Guanxi and ethical issues that Guanxi raises in S-S relationships. Several studies acknowledged that Guanxi can generate positive outcomes, for example, that supervisorsubordinate Guanxi is conducive to building trust in the supervisor (Han, Peng, \& Zhu, 2012). A recent study based on 281 supervisor-subordinate dyads in China found that Guanxi is strongly related to challenging organizational citizenship behavior (Zhang et al., 2015b). Leaders can use Guanxi networks to retain talented employees during merger and acquisition integration (Zhang et al., 2015a), but some studies have pointed out the ethical issues raised by Guanxi in S-S relationships (Han \& Altman, 2009). For example, the motives for building S-S Guanxi vary across a wide range of issues, with preference for personal benefits (Zhang, Deng, \& Wang, 2014). Another study identified job satisfaction as the mediating factor affecting the relation between S-S Guanxi and employee work outcomes (Cheung, Wu, Chan, \& Wong, 2009).

S-S Guanxi has both positive and negative sides. Some studies suggest that at times Chinese leadership emphasizes people and relationships more than it does job-related tasks (Warren, Dunfee, \& Li, 2004). But research has been examining Guanxi from the perspective of relational and personal gains, without focusing on organizational outcome. Even when exploring the influence of Guanxi on organizational performance (Luo et al., 2012), we cannot find explicit mention of the mechanisms by which Guanxi operates in S-S. Therefore, our focus on both individual career advancement and organizational performance is intended to elucidate the multi-level consequences of Guanxi in S-S based on a novel conceptualization of ambidextrous Guanxi.

\section{Ambidextrous Guanxi and traditional Chinese philosophy}

Research in organization and management studies urged paying attention to traditional philosophies and cultures while conducting indigenous management research (Holtbrügge, 
2013). Members of various cultures interpret, evaluate, and enact cultures and cultural manifestations in different ways because they have diverging interests, experiences, responsibilities, and values (Martin, Feldman, Hatch, \& Sitkin, 1983; Ravasi \& Schultz, 2006). Traditional philosophies embedded in various cultures are generally shared by members. The values of a society or organization can be identified by noting the issues on which members pass judgment or the principles on which they base their behavior. Some scholars have suggested that traditional Chinese philosophies, such as Taoism, Confucianism, and Legalism, have great potential for theoretically advancing contemporary leadership and management research (Ma \& Tsui, 2015).

We embraced this argument when resorting to traditional Chinese philosophies in order to conceptualize the notion of ambidextrous Guanxi. We seek to advance the Guanxi construct theoretically by emphasizing its philosophical foundations. In the Chinese management context, Guanxi has been widely examined from the point of view of its structure, principles, influence on Chinese business, and the ways in which it differs from Western networking (Liu et al., 2012a; Luo et al., 2012). A five-nation comparative study found similarities between Guanxi and other indigenous approaches that have achieved influence in business organizations (Smith et al., 2012). Although today Guanxi is widely used to represent reciprocity and social exchange in modern Chinese society, Guanxi as a social and personal relationship has been part of Chinese traditional culture for thousands of years. The fundamental meaning of Guanxi that represents a relationship between a supervisor and his subordinates (emperor vis-à-vis his ministers) can be traced to two ancient Chinese philosophical schools: Confucianism and Legalism.

For Confucians, Guanxi is based on five cardinal relationships. The fundamental ethics behind these relationships are based on sincerity, loyalty, and obligation. Leaders who display the virtue of benevolence, treat their subordinates as their own children, and take care of their 
welfare are obeyed by their subordinates and have earned their loyalty (Ling, Chia, \& Fang, 2000). Confucianism believes that loyalty based on virtue and morality is highly reliable because people identify with that virtue and perceive it as part of their inner selves (Feng, 2000).

In Chinese history, loyal Chinese ministers educated in a Confucian system chose to die rather than surrender to the enemy. For example, Gu Yan Wu (1613-1628) and Huang Zhong Xi (1610-1695), who were ministers in the Ming dynasty, chose to retire into the mountains after the collapse of the dynasty, in 1640, rather than accept the new emperor. They were both honored by the new rulers as "loyal and dutiful sons" of the previous ones. Some modern Chinese leaders have inherited this Confucian attitude. The Chinese supervisor is likely to establish a good relationship with a subordinate if he believes that the subordinate will remain loyal to him. For example, a newly promoted person tends to use his old staff because he believes that a subordinate who worked for him in difficult times is more likely to be loyal (Wei et al. 2010).

In contrast to Confucianism, Legalism emphasizes value exchange (Yu, 1987). Legalist thinking is utilitarian. It believes that reward and punishment are the most effective means of leadership (Yu, 1987; Feng, 2000). Legalism holds that emperors govern ministers by using political trickery, and ministers serve the emperor by using tactics. Recent research embracing this utilitarian perspective suggests that subordinates use political skill to establish good Guanxi with supervisors in order to advance their careers (Wei, Chiang, \& Wu, 2012; Douglas \& Ammeter, 2004) ). Although these studies have recognized political skill as one of the factors influencing Guanxi in supervisor-subordinate relationship, they ignored other factors inherited from Confucianism that also affect Chinese subordinates' use of Guanxi, such as loyalty.

\section{Conceptual framework}


The present study extends the line of inquiry into Guanxi by examining traditional Chinese culture and exploring S-S relationships in Chinese organizations. We argue that the S-S relationship in China is affected by philosophical tradition and ambidextrous Guanxi. We further argue that ambidextrous Guanxi is affected by philosophical tradition. We propose a conceptual framework by integrating the theoretical building blocks described above as shown in Figure 1.

\section{Insert Figure 1 about here}

Culture may be forgotten or misunderstood, but culture that is activated can become a resource that affects organizational life and individual behavior (Weber \& Dacin, 2011). When cultures are activated, they trigger the individuals' attention, encouraging them to interpret situations according to the rules of these cultures. This has the potential to affect their behavior, making them conform to cultural rules and social norms.

The philosophical foundation of Chinese culture affects the actions that managers undertook in dealing with their supervisors in Chinese organizations. We identified three theoretical dimensions in traditional Chinese philosophy that affect the S-S relationship: loyalty, dependence on supervisor, and work priority. The three dimensions embody the ambidexterity perspective by incorporating both Confucianism and Legalism in the effect they exercise on the S-S relationship. As a result, the implications of the S-S relationship on performance can be assessed both at the individual and at the organizational level. Our conceptual framework expands existing knowledge of Guanxi in S-S relationship by filtering the cultural resources perspective through an ambidexterity perspective. We argue that the presence of ambidextrous Guanxi may result in the S-S relationship affecting both individual- and organizational-level outcomes. In short, Confucianism and Legalism provide the philosophical foundations that enable ambidextrous Guanxi to manifest in the S-S relationship. This framework serves as the guideline for the present research. 
In sum, our research questions are: What are the mechanisms by which traditional Chinese cultures influence the S-S relationship from the ambidexterity perspective? What are the performance implications of Guanxi in the S-S relationship at the individual and organizational levels?

\section{Research method}

Our choice of a qualitative research method was determined by the nature of the research questions. The qualitative method has been widely used to understand emerging phenomena and constructs, especially when the new phenomenon cannot be adequately explained by existing theories (Morgan \& Smircich, 1980). Management and organization scholars have emphasized the importance and value of qualitative methods for theory extension (Doz, 2011; Eisenhardt \& Graebner, 2007). Leadership scholars have argued that the qualitative methodology is the cornerstone for understanding leadership (Conger, 1998). Despite the significant value of qualitative research in management and organization studies, the absence of a template for reporting on qualitative research (Pratt, 2009) demands scholarly creativity and imagination when conducting research of this nature. The qualitative research method incorporates the discovery process, resulting in what has been referred to as "generative research" (Locke, Golden-Biddle, \& Feldman, 2008).

The growing interest among scholars and practitioners in the applicability of qualitative research methods to international human resource management research has been reflected in several publications (Bagdadli, Hayton, \& Perfido, 2014; Melkonian, Monin, \& Noorderhaven, 2011; Xing, Liu, Tarba, \& Cooper, 2014), which are based on theoretical and methodological contributions in a cross-disciplinary field that includes discourse analysis, narratology, organization studies, and more (Vaara \& Tienari, 2011). The qualitative research method is conducive to capturing the complexity and nuances of HRM practices. For example, one recent study based on three cases of M\&As conducted by a single firm in Italy showed 
that the degree of HRM involvement in M\&A is contingent on the type of M\&A (Bagdadli et al., 2014). Another work using a qualitative case study method identified the distinctive characteristics of HRM practices from organizational, economic, and behavioral perspectives in the context of German small and medium-sized enterprises (SMEs) entering the Chinese market (Stokes et al., 2015a). The qualitative method made possible the identification and recognition of heterogeneity of HRM in SMEs, which contrasts with the coherent set of practices typically identified in the literature (Harney \& Dundon, 2006).

\section{Justification of storytelling as research method}

Storytelling is reemerging as research method, poised to reveal the nuances and underlying logic in many complex organization and management topics (Liu, Xing, \& Starik, 2012b). Different types of storytelling methods correspond to different epistemological assumptions (Rosile, Boje, Carlon, Downs, \& Saylors, 2013). Studies using storytelling as a research method often find revealing and even surprising results (Czarniawska, 2004; Gabriel, 2000, 2015). For example, in stories that capture the conflicting emotions of individuals, managers may appear as being both liked and disliked in their organizations based on multiple narrative accounts (Sims, 2005). Narrative approach to cultural analysis is particularly appealing because of its ability to capture the richness and complexity of inter-personal encounters in organizational life, and because of its capacity to go beyond what can be assessed using traditional sources of information, such as surveys and structured or semi-structured interviews. Scholars have urged organizational research to go the beyond formulaic methods and embrace greater diversity (Alvesson \& Gabriel, 2013). As the examination of Chinese overseas investment in African countries demonstrated, the storytelling method can help identify various HRM practices used by Chinese managers in supervising African employees (Xing et al., 2014). We therefore chose to conduct a biographical narrative study (Wengraf, 2001), with emphasis on a storytelling method. 
Storytelling as research method has excellent potential to advance scholarly inquiry into the S-S relationship both theoretically and methodologically. A recent study used storytelling to describe the S-S interaction (Klaussner, 2014). The storytelling narrative approach also enables researchers to grasp the managers' and employees' interviewed sense-giving and sense-making efforts in the organizational setting (Bartunek, Bobko, \& Venkatraman, 1993; Jokisaari \& Nurmi, 2009). Storytelling is conducive to capturing the nuances of cultural influences on managerial practices. For example, by soliciting and analyzing stories narrated by Chinese leaders, it was possible to identify the influence of the Taoist concept of wu wei on different leadership strategies (Xing \& Sims, 2012). Another recent study on Chinese mergers and corporate acquisitions used the storytelling method to articulate organizational and cultural influences on the connection between leaders' identity work and HRM involvement (Xing \& Liu, 2015). By using storytelling as a research method, we produce generative theoretical insights leading to a nuanced understanding of the S-S relationship and of the influences of traditional culture on this relationship.

\section{Sample and data collection}

Qualitative data were collected through in-depth narrative interviews with 28 Chinese middle and senior-level managers in SOEs. We chose SOEs as the sample of this study for three reasons: (a) SOEs, as opposed to privately-owned enterprises, have a distinct organizational culture that emphasizes relationship building; (b) SOE employees tend to have relatively longer career tenures than do employees in the highly fluctuating job markets, so that employees are likely to invest an effort in building and maintaining the SOEs relationship; (c) SOEs have undergone a series of reforms in China that affect individuals' career trajectory (Xing \& Liu, 2015a). In the midst of the Chinese enterprise modernization process and institutional transformation, SOEs remain an important player in contemporary Chinese economy, especially in the mainstay national industries, such as the financial sector and the 
utilities. At the same time, SOEs are different from the non-profit or public sector (Stokes et al., 2015b).

Most of the interviewees were managers aged approximately 40 to 45 . The three chairmen and one CEO were around 50 years old. We conducted open-ended narrative interviews to elicit the managers' practices as they in respect to the S-S relationship. We asked the interviewees to describe their relationship with supervisors and their working experiences in dealing with Guanxi. This narrative approach provided managers the opportunity to reflect on their past work and make sense of their present behaviors (Labov \& Waletzky, 1998). Table 1 lists the sample included in this study by a role-ordered matrix.

\section{Insert Table 1 about here}

Interviews consisted of two parts. In the first part, we asked, among others, for managers' views on their relationship with supervisors and their experiences dealing with Guanxi. In the second part we asked questions based on important points in their accounts in order to elicit more narratives on the S-S relationship. Each interview lasted two hours, and all the interviews were tape-recorded and transcribed.

We began the interviews by telling managers that we were interested in learning how they handled their relationships with supervisors. We indicated that we were particularly interested in how managers worked with supervisors to get things done, in managers' perceptions of their relationship with their supervisors, and in the manner in which this relationship affected their career advancement. We asked managers to tell us about their relationships with their supervisors at their workplace from the beginning of their career to the present. Although our question concerned the managers' relationships in the workplace, some also told us how they established a good relationship with their supervisors outside of work. To ensure the quality of our data, we conducted a rigorous analysis that enhanced the trustworthiness of our 
qualitative research (Gioia, Corley, \& Hamilton, 2013). We analyzed the narrative data using a comparative coding method. In the first open coding stage we identified practices and activities in dealing with the S-S relationship. In the second coding stage, we classified these practices into three dimensions related to traditional Chinese philosophical attitudes: loyalty, dependence on superiors, and work priority. Next, we identified statements relating to these three dimensions to show ambidextrous Guanxi in the S-S relationship. Finally, we situated these activities according to conceptual lenses of ambidexterity theory.

\section{Findings}

Below we describe the consolidated findings of our empirical study. before investigating the individual mechanisms underlying ambidextrous Guanxi in the S-S relationship. Both Confucianism and Legalism found empirical support in our data analysis. We use the term "ambidextrous Guanxi" to demonstrate the co-existence of two apparently contradictory philosophies, as we highlight their manifestations and consequences on career advancement and organizational performance. These manifestations are differentiated based on the three dimensions of loyalty, dependence on superiors, and work priority.

\section{Loyalty}

The Chinese traditional term "Wu Lun" (five cardinal relationships) meant something quite similar to Guanxi (King, 1991). In the conduct of "Wu Lun" and social intercourse ethically, Confucianism advocated four virtuous principles: ren (human-heartedness), yi (righteousness), $l i$ (ritual), and $z h i$ (wisdom) (Yu, 1987; Feng, 2000). Therefore a compelling arguments from Confucian perspective concerning the effects of Guanxi is that it promotes trust and loyalty.

According to Confucianism, loyalty should also be applied to the hierarchical relationship between the five cardinal relationships (between emperor and subjects, father and son, husband and wife, siblings, friends). One respectfully honorific title of the emperor is "Jun 
Fu" (father king), implying that loyalty to one's emperor is like loyalty to one's own father. The same loyalty also applies to one's relationship with teacher whom is respected as "Shi Fu" (teacher father). Therefore, in contrast to Legalism who emphasizes on loyalty to the country so as to use strict laws to regulate people's behavior, Confucianism advocates loyalty to individual leader who possess great virtue governing the country. It is for this reason that Meng Tzu, a most famous Confucian scholar (BC 372- BC 289) argued that if an emperor commit sorts of wickedness, followers should rebel him and put him to death $(<$ Meng Tzu: Liang Hui King>). It may be deemed as illegally by Legalism but righteously by Confucianism.

This Confucian view regarding loyalty still influences some modern Chinese leaders. Some managers we interviewed considered their career opportunity as a favor on the part of their personal superiors rather than their organization, and in return they worked hard simply not to disappoint their superiors. In other words, they perceived their loyalty as a commitment more to their individual superior than to the organization as a whole. One of the managers stated:

In this state owned company, you cannot force people to work overtime, especially to us old staff members, because we hold iron bowel (permanent job) and the senior managers have no right to fire employees. But if Tom (his senior manager) asked me to work overtime during holiday, I will do, simply for returning his recognition and kindness to me.

Because of this value orientation, when the manager was transferred to another department and worked for a new boss who took little interest in him, the manager might quickly lose his loyalty and interest in his work. This is because his work enthusiasm was closely tied to the relationship with his superior. 
Managers who subscribe to this value orientation tend to treat loyalty to superiors as fundamental to their career, prior to the loyalty to their organization. In this regard, loyalty means to "being part of the right team".

By contrast, other managers tend to pay little attention to the interest their boss takes in them and consider career opportunities as a reward for merit rather than as someone's favor. This value orientation places some managers on a confrontation path with their bosses. One manager narrated the following experience:

I only do things if it can benefit the firm, not the boss. Normally, the boss would prefer that you do things that make him look good. The team I am in charge of belongs to his department. The boss thought our achievement should bear his label. I disagree with this approach. I think we should do what is best for the organization. Therefore, conflicts between my boss and me are inevitable.

This story illustrates vividly the manager's concern for the organization rather than for his boss's personal interests. In contrast to the previous excerpt, the loyalty in this interviewee is to the organization. Individuals who care about the organization as a whole at the expense of their personal relationship with their supervisor do so with the understanding that this may harm their career advancement. Our empirical evidence illustrates the ambidextrous Guanxi that exists both at the individual and the organizational levels. Some individuals treat Guanxi as a career advancement tool, and therefore remain loyal to their superior. Others, however, have the organization as whole in mind, without much consideration of individual relationships. We argue, therefore, that Guanxi is a nuanced construct that applies both at the individual level and the organizational levels. An ambidexterity perspective of Guanxi may enhance our understanding of this complex, multi-level phenomenon. 
In light of the various interpretations that respondents ascribed to loyalty in ambidextrous Guanxi and to cultural influences and outcomes, we formulated the following propositions:

PROPOSITION 1a. Managers influenced by Confucianism tend to show loyalty to supervisors as an expression of ambidextrous Guanxi, expecting a positive influence on their career advancement.

PROPOSITION 1b. Managers influenced by Legalism tend to show loyalty to organizations as an expression of ambidextrous Guanxi, exerting a positive influence on organizational performance.

\section{Dependence on supervisors}

As discussed, leaders influenced by Confucianism expect their subordinates to show loyalty to them. Therefore, they pay close attention to how subordinates interact with them. For this reason, when leaders deal with their own supervisors, they also consider how to satisfy their supervisors and build a good relationship with them. Leaders who follow such a value orientation tend to show dependence on their supervisors and to believe that their superiors are trustworthy and their career advancement depends on a good relationship with their supervisor rather than on performance. This might explain why when sometimes one manager left, some of his or her pervious subordinates followed resignation. A junior manager stated:

"My previous department head was very hostile to me. Because I had good relationship with our vice president who was in charge of my department, he supported me to get rid of the department head. This year the vice president left our company, I will leave as well, either follow him or look for a new job."

By contrast, other managers although may attribute their success to their superiors' help, they see their career as independent from others: it is personal characteristics and individual contribution that matters for career advancement and success. This type of value orientation 
affects the managers' behavior in choosing their career path. One senior manager narrated the following story:

My previous department manager was very kind to me. He cared for growth of new staffs and assigned me into the team consist of many experts dealing with challenging projects. I learnt a lot. And I am very grateful. That means, you know, he likes me, to the extent that ... after I decided to leave my department and work in London branch, one day when I was sitting in front of my computer, my manager stood at my back quietly and touched my head saying, Andy, don't leave...he supported me a lot. But after careful consideration, I still chose to leave.

In this case, the manager differentiated personal relationship with superior from independency of his career path. Although many people may believe that a good established relation with the leader would have yielded positive returns for their future career, the interviewee choose to retain his independence and develop his career in a new branch. This value orientation affected his behavior and distanced him from his previous superior.

In the above narrative, the manager's value orientation is strongly influenced by Legalism: he is focused exclusively on organizational performance in developing his career caring little about maintaining good relationship with his previous supervisor. The typical Western transaction-oriented approach may find a philosophical foundation in traditional Chinese culture based on Legalism. Along this dimension, our qualitative evidence suggests two different types of orientation regarding career advancement: purely dependent upon the supervisor and based largely on merit and performance. The coexistence of both types provides empirical support for our conceptualization of ambidextrous Guanxi, rooted in Chinese philosophical traditions. 
In light of the variability that respondents demonstrated with regard to dependence on supervisor in ambidextrous Guanxi and to cultural influences and outcomes, we formulated the following propositions:

PROPOSITION 2a. Managers affected by Confucianism tend to show dependence on supervisors as an expression of ambidextrous Guanxi, exerting a positive influence on individual career advancement.

PROPOSITION 2b. Managers affected by Legalism tend to exhibit independence from supervisors as an expression of ambidextrous Guanxi, exerting a positive influence on organizational performance.

\section{Work Priority}

The third dimension that illustrates the differences in Guanxi in the S-S relationship has to do with work focus. Some managers tend to use their political skills to establish advanced relationships with their bosses, whereas others choose to strengthen their merits in business and gradually obtain recognition from their superiors therefore we propose ambidextrous Guanxi on work priority dimension.

We find that some managers' interest in using their political skills is affected by Legalism. Legalist thinking is utilitarian. Research by Wei and his colleagues (2010) conducted from a utilitarian perspective also suggests that managers use political skills to establish good Guanxi with supervisors (Wei, Liu, Chen, \& Wu, 2010). Our data show that managers affected by Legalism explore various types of their political skills with the belief that it is one of the most effective ways to advance their career. As mentioned by our interviewees, these types of political skills involve, exploring after work social actives with superiors through finding the same hobby, understanding the superior intention and obtaining a positive impression from 
him or her etc. Besides, to care for superiors' image and reputation may also obtain good impression from superiors. As narrated by one interviewee:

I need to deal with routine monitoring from the level above me carefully, such as reporting and finance. These things need to be done without any mistakes, because they are closely related to my boss's image and reputation. Therefore, if I guide people effectively in our department, handle reporting, finance, and HR well, our boss will be happy.

The manager emphasized the importance of using political skills to build Guanxi with his boss. He believes that it is crucial to consider the boss's image and reputation which may in turn make a positive impression on the boss. To these managers, relationship with the supervisors determines their careers. They spend significant amounts of time and efforts in building Guanxi, and deem Guanxi to be important for their successful career and promotion.

By contrast, other managers described themselves as "having no sense of pleasing the leaders," and criticized those who ignore business skills and focus only on seeking connections. In their opinion, these managers cannot hold their position for long, and their careers are similar to "castles in the air." As indicated in one manger's story.

I don't have any background or family resources that I could use for my professional career. At every step I have to overcome obstacles. My supervisor didn't play a key role in my career development. It wasn't because others put me in some good spot, but my own ability and skillset. What I'm concerned with is how our firm is doing, not the relationship with the bosses.

Managers who consider their merits to be more important than Guanxi are more likely to survive the difficulties and frustrations that originate with their supervisors or their work because their motivation for work is not driven by pleasing supervisors or forming a good 
relationship, but by increasing their own merits. Compared to managers who emphasize building Guanxi through political skill, managers who treat their merits as more important are more likely to develop an independent attitude toward their career success and promotion. Moreover, some managers have pointed out the unexpected consequences and unpredictability of relying on Guanxi relationships. One manager put it as follows:

If you deliberately act to please the boss, it might not lead to the expected outcome. For example, if you head toward the East to accommodate the boss, you may find that the boss aims for the West. Therefore, it is your performance, work quality, and integrity that determine your career. Eventually, the boss will like you because of your performance.

In the above narrative, the manager stated that his priority at work is merit rather than political skills in dealing with his supervisor. In his opinion, in the long term, it is merit and performance that determine career advancement. Such a value orientation, affected by Legalism, is likely to contribute positively to organizational performance.

Based on our data analysis, we suggest that ambidextrous Guanxi is present in the work priority dimension. Variations in the managers' focus with regard to their work illustrate their value orientation in the career advancement. Both views are present with regard to their career advancement, depending on whether the emphasis is on political skill or performance and merits. Ambidextrous Guanxi shows that Chinese managers can adopt both approaches in the pursuit of their career advancement. Based on the variations in responses regarding work priority in ambidextrous Guanxi, and on the cultural influences and outcomes of these variations, we formulated the following propositions:

PROPOSITION 3a. Managers affected by Legalism tend to emphasize political skill as a work priority as an expression of ambidextrous Guanxi, exerting a positive influence on individual career advancement. 
PROPOSITION 3b. Managers affected by Confucianism tend to emphasize merit as a work priority as an expression of ambidextrous Guanxi, exerting a positive influence on organizational performance.

Table 2 presents an overview of ambidexterity in the S-S relationship, showing selective empirical evidence along the three dimensions of loyalty, dependence on superiors, and work priority.

Insert Table 2 about here

\section{Conceptual framework including propositions}

Insert Figure 2 about here

Based on the findings and the narrative evidence presented above, we expanded the conceptual framework of the study through the three pairs of propositions. Figure 2 shows the expanded conceptual model. The first pair of propositions concerns the effect of Chinese traditional culture on loyalty. Confucianism affects individuals' preference by tilting the balance toward loyalty to individual supervisor in the S-S relationship, which in turn can positively affect the individual's career advancement (P1a), whereas Legalism tilts the balance toward loyalty to the organization, which in turn can positively affect organizational performance $(\mathrm{P} 1 \mathrm{~b})$. The second pair of propositions focuses on the effect of traditional culture on dependence on supervisors. Confucianism encourages dependence on supervisors in the S$\mathrm{S}$ relationship, which in turn can positively affect the individual's career advancement, (P2a), whereas Legalism encourages independence from supervisors, which in turn can positively affect organizational performance $(\mathrm{P} 2 \mathrm{~b})$. The third pair of propositions deals with the influence of traditional culture on work priority. Legalism motivates individuals to prioritize political skill in the S-S relationship, which in turn can positively affect the individual's career advancement (P3a), whereas Confucianism motivates individuals to prioritize performance 
and merit, which in turn can positively affect organizational performance (P3b). In the case of P1a and P2a, the influence of Confucianism leads to individual-level career advancement, whereas in the case of $\mathrm{P} 3 \mathrm{~b}$, the influence of Confucianism leads to organizational-level performance. The same logic applies to P1b and P2b, where the influence of Legalism leads to organizational-level performance, whereas in $\mathrm{P} 3 \mathrm{a}$, the influence of Legalism leads to individual-level career advancement. The apparently contradictory observations attest to the ambidextrous characteristics of Guanxi, which under the influence of either Confucianism or Legalism can achieve both individual-level career advancement and organizational-level performance, depending on the different dimensions of ambidextrous Guanxi. Collectively, the propositions illustrate the variations in ambidextrous Guanxi, as they are influenced by either Confucianism or Legalism. The influences of traditional culture lead to diverging outcomes both at the individual level (career advancement) and the organizational level (performance).

\section{Discussion and implications}

\section{Theoretical contribution}

The present research contributes to the emerging literature on ambidexterity and HRM by (a) investigating inter-personal relationships at the individual level from an ambidexterity perspective, (b) taking a comparative look at Chinese tradtional cultures and their influence on Guanxi in the S-S relationship, and (c) identifying variations within Guanxi (based on a cultural and philosophical explanation) in the way in which it affects individual- and organization-level outcomes. Recent research on ambidexterity and HRM has moved down the level of analysis from that of organizations, such as business unit ambdiexterity (Chebbi et al., 2015), to individual ambidexterity (Rogan \& Mors, 2014). For example, drawing on case studies of three mid-size "hidden champions" in various high-tech manufacturing sectors, Garaus, Güttel, Konlechner, Koprax, Lackner, Link, and Müller (2015) showed that ambidextrous HRM systems can be regarded as a special type of high-performance work 
system that facilitates the continuous integration of exploration and exploitation in the pursuit of flexibility and efficiency. The authors explained how the focal firms apply integrative employment practices and integrative work practices in order to facilitate collaboration and to build and solidify a common frame of reference that fosters knowledge integration, reconciling the contradictory demands of the exploration and exploitation processes. Based on a survey conducted among managers of two large firms, Mom, Fourne, and Jansen (2015) examined organizational and functional tenure as important antecedents of ambidexterity at the individual level, and provided unique insights into the contextual conditions under which the ambidextrous behavior of managers contributes to individual performance. They also pointed to the fact that whereas organizational tenure contributes to managers' ambidextrous behavior, functional tenure limits such complex behavior, and explained how managers' ambidextrous behavior contributes to individual performance in uncertain and interdependent work contexts (Mom, Fourne, \& Jansen, 2015). A recent study by Burgess, Strauss, Currie, and Wood (2015) examined the influence of prevailing tensions and competing agendas characteristic of a professionalized, public-sector context on knowledge exploitation and exploration at the middle levels of the organization, and explored how these tensions are experienced and reconciled at the individual level. The study investigated the contextual and personal circumstances that enable hybrid middle managers to forge workable compromises between exploration and exploitation in order to facilitate ambidexterity. But little attention has been paid to the mechanisms that drive ambidextrous behaviors at the inter-personal level. Our findings extend the body of knowledge on ambidexterity and HRM, showing how an ambidexterity perspective can advance our understanding of Guanxi in the S-S relationship. Our study also explains how the ambidexterity literature can advance Guanxi literature from a cultural perspective, in the context of the S-S relationship. We have shown that the influences of Confucianism and Legalism are manifested through two value orientations, relation- and merit-based. We examined the nuances and complexity of traditional cultural influences 
through three dimensions of the S-S relationship: loyalty, dependence on supervisors, and work priority. Our study contributes theoretically to the ambidexterity literature by offering an initial attempt to bridge ambidexterity and the S-S relationship in the HRM domain.

Traditoinal cultures can affect organizational and individual behavior in contemporary business practice and in society at large (Xing \& Liu, 2015). Scholars suggest that culture can become a resource for organizations and for individuals, to act upon and make sense of their environment (Weber \& Dacin, 2011). Using traditional Chinese philosophy, we show that in the S-S relatioship individuals' preferece in the way they perceive Guanxi is affected by Confucianism and Legalism. Our findings add to the understanding of how " traditional Chinese philosophies can affect contemporary practice" (Ma \& Tsui, 2015). Our research emphasizes the influence of traditional culture and its implications for the S-S relatioship in emerging economies, expanding existing empirical findings. It lends support to the arguement that Chinese classical thought and contempoary management studies share many commonalities (Rhee, 2010) in the context of the S-S relationship and of HRM in general.

Our research also contributes to the broader literature on Guanxi and HRM (Zhang et al., 2015a) in emerging economies by examining the S-S relationship in Chinese organizations. The conceptualization of ambidextrous Guanxi extends the literature on Guanxi by examining both the relation- and merit-based approaches. The present study also reveals the link between Chinese traditional culture and Guanxi in the S-S relationship and contributes to the Guanxi literature (Luo et al., 2012) by elucidating the merit- and performance-oriented side of Guanxi, which is almost absent from the literature. We argue that the ambidexterity perspective can theoretically advance the Guanxi literature. Our research examines closely the role of Guanxi from the ambidexterity persepctive of affecting individual career advancement and organizational performance. The findings show the variations in outcome level in Chinese organizations based on a cultural and philosophical explanation. 


\section{Managerial implications}

Our findings contain important implications for managers dealing with the S-S relationship in organizations. The approach according to which building Guanxi through political skill is important for promotion, redirects managers' motivation from satisfying the needs of the organization to satisfying their supervisors' needs. Managers following this type of approach tend to spend most of their time on dealing with Guanxi and developing political skills, which decreases their involvement and engagement in their actual work. Studying managers' work motivation based on their approaches toward Guanxi can help supervisors manage and train their subordinates. Supervisors should not simply evaluate subordinates based on their superficial performance, but consider their intentions, in order to manage and control them more effectively. Our study reveals an alternative perspective of Guanxi, which is concerned with organizational performance rather than individual supervisors. Guanxi can therefore be recognized as a strategic $\mathrm{HR}$ asset that can be used both for personal benefits and for organizational performance. Our study resonates with the recent call for passion and care in the organization (Rynes, Bartunek, Dutton, \& Margolis, 2012). Adopting the ambidexterity perspective, it is possible to care both for oneself and for the organization as a whole in dealing with the S-S relationship.

The study stresses the influence of traditional culture on the behavior of Chinese managers. Addressing the recent view about traditional culture affecting managers' HRM practices (Xing et al., 2014), we suggest a nuanced and contextualized understanding of traditional cultures, which can assist managers in cultivating cultural intelligence when conducting business across geographic and national boundaries. In today's fast-changing and increasingly interconnected global society, the collective wisdom of East and West can better prepare managers for adopting a multicultural mindset (Chen, 2014) in the face of unprecedented challenges. Our findings shed light on how traditional Chinese culture and philosophy affect managers' behaviors in dealing with inter-personal relationships. Managers can use our 
findings when dealing with Chinese supervisors and subordinates. It is possible to derive individual benefits and achieve organizational performance by becoming an ambidextrous manager (Tushman, Smith, \& Binns, 2011). A nuanced understanding of Guanxi from the cultural and philosophical perspective offers food for thought, and can both inform and affect practice.

\section{Future research directions}

Our study focuses on the cultural and philosophical foundations of ambidextrous Guanxi, and its manifestation in the S-S relationship. Several potential venues for further research await scholarly inquiry. First, researchers can focus on the S-S relationship in other complex organizational forms, such as inter-organizational collaborative partnerships, to determine whether our results can be generalized beyond the current empirical setting. An important extension involves investigating inter-personal relationship and HRM practices in mergers and acquisitions (Sarala, Junni, Cooper, \& Tarba, 2014; Xing \& Liu, 2015a), and their consequences for organizational performance. Second, in addition to Confucianism and Legalism and their implications, further research can investigate other philosophical trends affecting Chinese organizations, for example, Taoism (Xing \& Sims, 2012). Researchers could develop a more nuanced model of Guanxi in the S-S relationship by exploring the interaction effects between various Chinese philosophical approaches. We recommend a culture-as-resource perspective that includes both national and organizational cultures. Third, our study of Guanxi in the S-S relationship is closely related to ambidexterity. But the phenomenon may be explained by a range of alternative or competing theories, for example, the paradox theory (Andriopoulos \& Lewis, 2009; Smith, 2014; Smith, Binns, \& Tushman, 2010; Smith \& Lewis, 2011; Yoon, \& Chae, 2012). A cross-fertilization approach between ambidexterity and paradox may prove a fruitful line of inquiry, especially in the context of Chinese organizations and organizational behaviors, with their rich traditional and cultural resources, and philosophical thinking. 


\section{Conclusions}

The present study explores the cultural and philosophical foundations of Guanxi in the S-S relationship from the ambidexterity perspective. Our study articulates the three dimensions of ambidextrous Guanxi-loyalty, dependence on supervisor, and work priority, on which the S$\mathrm{S}$ relationship in Chinese organizations is based. We describe the variations in Guanxi and its traditional Chinese cultural background, Confucianism and Legalism. Our research suggests that relation-based Guanxi alone is not enough to capture the complexity of Guanxi in Chinese organizations; rather, a combination of relation- and merit-based Guanxi, examined from the ambidexterity perspective, can explain the variation in its manifestations. Our findings also shed light on the consequences of Guanxi in the S-S relationship at both the individual and organizational levels. In view of the increasing importance of caring within the organization and of sustainable development, a nuanced and contextualized understanding of Guanxi can better prepare managers for meeting both individual and organizational expectations. Our study can stimulate the intellectual discourse on the influences of Chinese philosophy on contemporary management and organization studies, with the promising potential of informing and affecting practice.

\section{References}

Ahammad, F. M., Lee, M. S., Malul, M., \& Shoham, A. 2015. Behavioral Ambidexterity: The Impact of Incentive Schemes on Productivity, Motivation, and Performance of Employees in Commercial Banks. Human Resource Management.

Alvesson, M., \& Gabriel, Y. 2013. Beyond formulaic research: In praise of greater diversity in organizational research and publications. Academy of Management Learning \& Education, 12(2): 245-263.

Andriopoulos, C., \& Lewis, M. (2009). Exploitation-exploration tensions and organizational ambidexterity: Managing paradoxes of innovation. Organization Science, 20: 696717.

Bagdadli, S., Hayton, J. C., \& Perfido, O. 2014. Reconsidering the Role of HR in M\&As: What Can Be Learned From Practice. Human Resource Management, 53(6): 10051025 .

Bartunek, J. M., Bobko, P., \& Venkatraman, N. 1993. Toward innovation and diversity in management research methods. Academy of Management Journal, 36(6): 1362-1373. 
Birkinshaw, J., \& Gupta, K. 2013. Clarifying the Distinctive Contribution of Ambidexterity to the Field of Organization Studies. Academy of Management Perspectives, 27(4): 287298.

Boisot, M., \& Child, J. 1996. From fiefs to clans and network capitalism: Explaining China's emerging economic order. Administrative Science Quarterly, 41(4): 600-628.

Bozionelos, N., \& Wang, L. 2006. The relationship of mentoring and network resources with career success in the Chinese organizational environment. The International Journal of Human Resource Management, 17(9): 1531-1546.

Burgess, N., Strauss, K., Currie, G., \& Wood, G. (2015). Organizational ambidexterity and the hybrid middle manager: The case of patient safety in UK hospitals. Human Resource Management, DOI: 10.1002/hrm.21725.

Cao, Q., Simsek, Z., \& Zhang, H. 2010. Modeling the joint impact of the CEO and the TMT on organizational ambidexterity. Journal of Management Studies, 47: 1272-1296.

Carmeli, A., \& Halevi, M. 2009. How top management team behavioral integration and behavioral complexity enable organizational ambidexterity: The moderating role of contextual ambidexterity. Leadership Quarterly, 20: 207-218.

Cegarra-Navarro, J.,\& Dewhurst, F. 2007. Linking organizational learning and customer capital through an ambidexterity context: an empirical investigation in SMEs. International Journal of Human Resource Management, 18 (10): 1720-1735.

Chang, Y.-Y. 2015. A multilevel examination of high-performance work systems and unitlevel organizational ambidexterity. Human Resource Management Journal, 25 (1): 79-101.

Chebbi, H., Yahiaoui, D., Vrontis, D., \& Thrassou, A. 2015. Building Multiunit Ambidextrous Organizations-A Transformative Framework. Human Resource Management.

Chen, M.-J. 2014. Presidential Address-Becoming Ambicultural: A Personal Quest, and Aspiration for Organizations. Academy of Management Review, 39(2): 119-137.

Chen, M. J. 2002. Transcending paradox: The Chinese "middle way" perspective. Asia Pacific Journal of Management, 19(2): 179-199.

Chen, Y. F., \& Tjosvold, D. 2006. Participative Leadership by American and Chinese Managers in China: The Role of Relationships*. Journal of Management Studies, 43(8): 1727-1752.

Chermack, T. J., Bodwell, W., \& Glick, M. 2010. Two Strategies for Leveraging Teams Toward Organizational Effectiveness: Scenario Planning and Organizational Ambidexterity. Advances in Developing Human Resources, 12 (1): 137-156 .

Cheung, M. F. Y., Wu, W. P., Chan, A. K. K., \& Wong, M. M. L. 2009. Supervisorsubordinate guanxi and employee work outcomes: The mediating role of job satisfaction. Journal of Business Ethics, 88: 77-89.

Chua, R. Y., Morris, M. W., \& Ingram, P. 2009. Guanxi vs networking: Distinctive configurations of affect-and cognition-based trust in the networks of Chinese vs American managers. Journal of International Business Studies, 40(3): 490-508.

Conger, J. A. 1998. Qualitative research as the cornerstone methodology for understanding leadership. The Leadership Quarterly, 9(1): 107-121.

Czarniawska, B. 2004. Narratives in social science research. London: Sage.

Douglas, C., \& Ammeter, A. P. 2004. An examination of leader political skill and its effect on ratings of leader effectiveness. The Leadership Quarterly, 15(4): 537-550.

Doz, Y. 2011. Qualitative research for international business. Journal of International Business Studies, 42(5): 582-590.

Dulebohn, J. H., Bommer, W. H., Liden, R. C., Brouer, R. L., \& Ferris, G. R. 2012. A metaanalysis of antecedents and consequences of leader-member exchange integrating the past with an eye toward the future. Journal of Management, 38(6): 1715-1759. 
Eisenhardt, K. M., \& Graebner, M. E. 2007. Theory building from cases: Opportunities and challenges. Academy of Management Journal, 50(1): 25-32.

Feng, Y. 2000. Zhong Guo Zhe Xue Shi (The history of Chinese philosophy). : Hua Dong Shi Da University Pub.

Filippini, R., Güttel, W. H., \& Nosella, A. 2012. Ambidexterity and the evolution of knowledge management initiatives. Journal of Business Research, 65(3): 317-324.

Gabriel, Y. 2000. Storytelling in Organizations: Facts, Fictions, and Fantasies: Facts, Fictions, and Fantasies. Oxford: Oxford University Press.

Gabriel, Y. 2015. Narratives and Stories in Organizational Life. In A. De Fina, \& A. Georgakopoulou (Eds.), The Handbook of Narrative Analysis: 275-292. West Sussex: Wiley Blackwell.

Garaus, C., Güttel, W. H., Konlechner, S., Koprax, I., Lackner, H., Link, K. \& Müller, B. 2015. Bridging knowledge in ambidextrous HRM systems: Empirical evidence from hidden champions, The International Journal of Human Resource Management, DOI: 10.1080/09585192.2015.1045007

George, G. 2014. Rethinking management scholarship. Academy of Management Journal, 57(1): 1-6.

Gephart, R. P. 2004. Qualitative research and the Academy of Management Journal. Academy of Management Journal, 47(4): 454-462.

Gioia, D. A., Corley, K. G., \& Hamilton, A. L. 2013. Seeking qualitative rigor in inductive research notes on the Gioia methodology. Organizational Research Methods, 16(1): 15-31.

Good, D., \& Michel, E. J. 2013. Individual ambidexterity: Exploring and exploiting in dynamic contexts. Journal of Psychology: Interdisciplinary and Applied, 147 (5): 435-453, DOI: 10.1080/00223980.2012.710663

Halevi, M., Carmeli, A., \& Brueller, N. 2015. Ambidexterity in SBUs: Top Management Team Integration and Environmental Dynamism. Human Resource Management, DOI: $10.1002 / \mathrm{hrm} .21665$

Han, Y., \& Altman, Y. 2009. Supervisor and subordinate Guanxi: a grounded investigation in the People's Republic of China. Journal of Business Ethics, 88: 91-104.

Han, Y., Peng, Z., \& Zhu, Y. 2012. Supervisor-subordinate guanxi and trust in supervisor: A qualitative inquiry in the People's Republic of China. Journal of Business Ethics, 108(3): 313-324.

Harney, B., \& Dundon, T. 2006. Capturing complexity: developing an integrated approach to analysing HRM in SMEs. Human Resource Management Journal, 16(1): 48-73.

Heavey, C., Simsek, Z., \& Fox, B. C. 2015. Managerial Social Networks and Ambidexterity of SMEs: The Moderating Role of a Proactive Commitment to Innovation. Human Resource Management, DOI:10.1002/hrm.21703.

Hofstede, G., \& Bond, M. H. 1984. Hofstede's culture dimensions. Journal of Cross-Cultural Psychology, 15(4): 417-433.

Holtbrügge, D. 2013. Indigenous management research. Management International Review, 53(1): 1-11.

Huang, J., \& Kim, H.J. 2013. Conceptualizing structural ambidexterity into the innovation of human resource management architecture: The case of LG Electronics. International Journal of Human Resource Management, 24 (5): 922-943.

Jia, L., You, S., \& Du, Y. 2012. Chinese Context and Theoretical Contributions to Management and Organization Research: A Three-decade Review. Management and Organization Review, 8(1): 173-209.

Jokisaari, M., \& Nurmi, J.-E. 2009. Change in newcomers' supervisor support and socialization outcomes after organizational entry. Academy of Management Journal, 52(3): 527-544. 
Junni, P., Sarala, R. M., Taras, V., \& Tarba, S. Y. 2013. Organizational Ambidexterity and Performance: A Meta-Analysis. Academy of Management Perspectives, 27(4): 299312.

Junni, P., Sarala, R. M., Tarba, S. Y., Liu, Y., \& Cooper, C.L. 2015. Guest Editors' Introduction: The Role of Human Resources and Organizational Factors in Ambidexterity. Human Resource Management, 54(S1): S1-S28.

Klaussner, S. 2014. Engulfed in the abyss: The emergence of abusive supervision as an escalating process of supervisor-subordinate interaction. Human Relations, 67(3): 311-332.

Kostopoulos, K. C., Bozionelos, N., \& Syrigos, E. 2015. Ambidexterity and unit performance: Intellectual capital antecedents and cross-level moderating effects of human resource practices. Human Resource Management, DOI:10.1002/hrm.21705

Labov, W., \& Waletzky, J. 1998. Narrative Analysis: Oral Versions of Personal Experience. Oral Versions of Personal Experience: Three Decades of Narrative Analysis. A Special Issue of the Journal of Narrative and Life History, 7: 3.

Law, K. S., Wong, C.-S., Wang, D., \& Wang, L. 2000. Effect of supervisor-subordinate guanxi on supervisory decisions in China: An empirical investigation. International Journal of Human Resource Management, 11(4): 751-765.

Ling, W., Chia, R. C., \& Fang, L. 2000. Chinese implicit leadership theory. The Journal of Social Psychology, 140(6): 729-739.

Liu, Y., Woywode, M., \& Xing, Y. 2012a. High technology start-up innovation and the role of guanxi: an explorative study in China from an institutional perspective.

Prometheus, 30(2): 211-229.

Liu, Y., Xing, Y., \& Starik, M. 2012b. Storytelling as Research Method: A West-Meets-East Perspective. In C. L. Wang, J. D. Ketchen, \& D. D. Bergh (Eds.), Research Methodology in Strategy and Management Vol. 7: Emerald Group Pub Ltd.

Locke, K., Golden-Biddle, K., \& Feldman, M. S. 2008. Perspective-making doubt generative: rethinking the role of doubt in the research process. Organization Science, 19(6): 907918.

Lubatkin, M. H., Simsek, Z., Ling, Y., \& Veiga, J. F. 2006. Ambidexterity and performance in small- to medium-sized firms: The pivotal role of top management team behavioral integration. Journal of Management, 32 (5), 646-672.

Luo, Y., Huang, Y., \& Wang, S. L. 2012. Guanxi and organizational performance: a meta-analysis. Management and Organization Review, 8(1): 139-172.

Luo, Y., \& Rui, H. 2009. An ambidexterity perspective toward multinational enterprises from emerging economies. Academy of Management Perspectives, 23(4): 49-70.

Ma, L., \& Tsui, A. S. 2015. Traditional Chinese philosophies and contemporary leadership. The Leadership Quarterly, 26(1): 13-24.

March, J. G. 1991. Exploration and exploitation in organizational learning. Organization Science, 2(1): 71-87.

Martin, J., Feldman, M. S., Hatch, M. J., \& Sitkin, S. B. 1983. The uniqueness paradox in organizational stories. Administrative Science Quarterly: 438-453.

Melkonian, T., Monin, P., \& Noorderhaven, N. G. 2011. Distributive justice, procedural justice, exemplarity, and employees' willingness to cooperate in M\&A integration processes: An analysis of the Air France-KLM merger. Human Resource Management, 50(6): 809-837.

Mihalache, O.R., Jansen, J.J.P., Van Den Bosch, F.A.J., \& Volberda, H.W. 2014. Top management shared leadership and organizational ambidexterity: A moderated mediation framework. Strategic Entrepreneurship Journal, 8, 128-148. 
Mizrachi, N., Drori, I., \& Anspach, R. R. 2007. Repertoires of trust: The practice of trust in a multinational organization amid political conflict. American Sociological Review, 72(1): 143-165.

Mom, T. J. M., Fourne, S. P. L., \& Jansen, J. J. P. 2015. Managers' work experience, ambidexterity and performance: The contingency role of the work context. Human Resource Management, DOI:10.1002/hrm.21663.

Morgan, G., \& Smircich, L. 1980. The case for qualitative research. Academy of Management Review, 5(4): 491-500.

Munyon, T. P., Summers, J. K., Thompson, K. M., \& Ferris, G. R. 2015. Political Skill and Work Outcomes: A Theoretical Extension, Meta-Analytic Investigation, and Agenda for the Future. Personnel Psychology, 68(1): 143-184.

Nee, V. 1992. Organizational dynamics of market transition: Hybrid forms, property rights, and mixed economy in China. Administrative Science Quarterly, 37(1): 1-27.

O’Reilly, C. A., Bruce, H. J., \& Tushman, M. L. 2009. Organizational ambidexterity: IBM and emerging business opportunities. California Management Review, 51: 1-25.

O'Reilly, C. A., \& Tushman, M. L. 2004. The ambidextrous organization. Harvard Business Review, April: 74-83.

O'Reilly, C. A., \& Tushman, M. L. 2013. Organizational Ambidexterity: Past, Present, and Future. Academy of Management Perspectives, 27(4): 324-338.

Park, S. H., \& Luo, Y. 2001. Guanxi and organizational dynamics: organizational networking in Chinese firms. Strategic Management Journal(22): 455-477.

Patel, P. C., Messersmith, J. G., \& Lepak, D. P. 2013. Walking the Tightrope: An Assessment of the Relationship between High-Performance Work Systems and Organizational Ambidexterity. Academy of Management Journal, 56(5): 1420-1442.

Pratt, M. G. 2009. From the editors: For the lack of a boilerplate: Tips on writing up (and reviewing) qualitative research. Academy of Management Journal, 52(5): 856-862.

Prieto, I. M., \& Santana, P. P. M. 2012. Building ambidexterity: The role of human resource practices in the performance of firms from Spain. Human Resource Management, 51(2): 189-211.

Prieto-Pastor, I., \& Martin-Perez, V. 2014. Does HRM generate ambidextrous employees for ambidextrous learning? The moderating role of management support. International Journal of Human Resource Management, http://dx.doi.org/10.1080/09585192.2014.938682

Raisch, S., \& Birkinshaw, J. 2008. Organizational ambidexterity: Antecedents, outcomes, and moderators. Journal of Management, 34: 375-409.

Ravasi, D., \& Schultz, M. 2006. Responding to organizational identity threats: Exploring the role of organizational culture. Academy of Management Journal , 49(3): 433-458.

Rhee, M. 2010. The pursuit of shared wisdom in class: When classical Chinese thinkers meet James March. Academy of Management Learning \& Education, 9(2): 258-279.

Rogan, M., \& Mors, M. L. 2014. A Network Perspective on Individual-Level Ambidexterity in Organizations. Organization Science, 25(6): 1860-1877.

Rosile, G. A., Boje, D. M., Carlon, D. M., Downs, A., \& Saylors, R. 2013. Storytelling Diamond An Antenarrative Integration of the Six Facets of Storytelling in Organization Research Design. Organizational Research Methods, 16(4): 557-580.

Rynes, S. L., Bartunek, J. M., Dutton, J. E., \& Margolis, J. D. 2012. Care and Compassion Through an Organizational Lens: Opening Up New Possibilities. Academy of Management Review, 37(4): 503-523.

Sarala, R. M., Junni, P., Cooper, C. L., \& Tarba, S. Y. 2014. A sociocultural perspective on knowledge transfer in mergers and acquisitions. Journal of Management, Published online before print April 16, 2014. 
Sims, D. 2005. You bastard: A narrative exploration of the experience of indignation within organizations. Organization Studies, 26(11): 1625-1640.

Simsek, Z. 2009. Organizational ambidexterity: Towards a multilevel understanding. Journal of Management Studies, 46(4): 597-624.

Smith, P. B., Torres, C., Leong, C.-H., Budhwar, P., Achoui, M., \& Lebedeva, N. 2012. Are indigenous approaches to achieving influence in business organizations distinctive? A comparative study of guanxi, wasta, jeitinho, svyazi and pulling strings. The International Journal of Human Resource Management, 23(2): 333-348.

Smith, W. K. 2014. Dynamic decision making: A model of senior leaders managing strategic paradoxes. Academy of Management Journal, 57(6): 1592-1623.

Smith, W. K., Binns, A., \& Tushman, M. L. 2010. Complex business models: Managing strategic paradoxes simultaneously. Long Range Planning, 43(2/3): 448-461.

Smith, W. K., \& Lewis, M. W. 2011. Toward a theory of paradox: A dynamic equilibrium model of organizing. Academy of Management Review, 36(2): 381-403.

Smith, W. K., \& Tushman, M. L. 2005. Managing strategic contradictions: A top management model for managing innovation streams. Organization Science, 16 (5): 522-536.

Stokes, P., Liu, Y., Smith, S., Leidner, S., Moore, N., \& Rowland, C. 2015a. Managing talent across advanced and emerging economies: HR issues and challenges in a SinoGerman strategic collaboration. The International Journal of Human Resource Management, DOI: 10.1080/09585192.2015.1074090.

Stokes, P., Moore, N., Moss, D., Mathews, M., Smith, S. M., \& Liu, Y. 2015b. The Micro-Dynamics of Intraorganizational and Individual Behavior and Their Role in Organizational Ambidexterity Boundaries. Human Resource Management, Forthcoming.

Styles, C., \& Ambler, T. 2003. The coexistence of transaction and relational marketing: Insights from the Chinese business context. Industrial Marketing Management, 32(8): 633-642.

Swidler, A. 1986. Culture in action: Symbols and strategies. American Sociological Review, 51: 273-286.

Turner, N., \& Lee-Kelley, L. 2012. Unpacking the theory on ambidexterity: An illustrative case on the managerial architectures, mechanisms and dynamics. Management Learning, 44 (2): 179-196.

Turner, N., Swart, J., \& Maylor, H. 2013. Mechanisms for managing ambidexterity: a review and research agenda. International Journal of Management Reviews, 15(3): 317-332.

Tushman, M. L., Smith, W. K., \& Binns, A. 2011. The ambidextrous CEO. Harvard Business Review, 89(6): 74-80, 136.

Vaara, E., \& Tienari, J. 2011. On the narrative construction of MNCs: An antenarrative analysis of legitimation and resistance in a cross-border merger. Organization Science, 22(2): 370-390.

Wang, C. L., \& Rafiq, M. 2012. Ambidextrous organizational culture, contextual ambidexterity and new product innovation: A comparative study of UK and Chinese high-tech firms. British Journal of Management, 25 (1): 58-76.

Warren, D. E., Dunfee, T. W., \& Li, N. 2004. Social exchange in China: The double-edged sword of guanxi. Journal of Business Ethics, 55(4): 353-370.

Weber, K., \& Dacin, M. T. 2011. The cultural construction of organizational life: Introduction to the special issue. Organization Science, 22(2): 287-298.

Wei, L. Q., Chiang, F. F., \& Wu, L. Z. 2012. Developing and utilizing network resources: Roles of political skill. Journal of Management Studies, 49(2): 381-402.

Wei, L. Q., Liu, J., Chen, Y. Y., \& Wu, L. Z. 2010. Political skill, supervisor-subordinate guanxi and career prospects in Chinese firms. Journal of Management Studies, 47(3): 437-454. 
Wengraf, T. 2001. Qualitative research interviewing: Biographic narrative and semistructured methods. London: Sage Publications Ltd.

Wong, Y.-T., Wong, S.-H., \& Wong, Y.-W. 2010. A study of subordinate-supervisor guanxi in Chinese joint ventures. The International Journal of Human Resource Management, 21(12): 2142-2155.

Xin, K. K., \& Pearce, J. L. 1996. Guanxi: Connections as substitutes for formal institutional support. Academy of Management Journal, 39(6): 1641-1658.

Xing, Y., \& Liu, Y. 2015a. Linking leaders' identity work and human resource management involvement: The case of sociocultural integration in Chinese mergers and acquisitions. The International Journal of Human Resource Management, Forthcoming.

Xing, Y., \& Liu, Y. 2015b. Poetry and Leadership in Light of Ambiguity and Logic of Appropriateness. Management and Organization Review, 11 (4), 763 - 793.

Xing, Y., Liu, Y., Tarba, S. Y., \& Cooper, C. L. 2014. Intercultural Influences on Managing African Employees of Chinese Firms in Africa: Chinese Managers' HRM Practices. International Business Review, online June 25.

Xing, Y., \& Sims, D. 2012. Leadership, Daoist Wu Wei and reflexivity: Flow, self-protection and excuse in Chinese bank managers' leadership practice. Management Learning, 43(1): 97-112.

Yoon, S.J., \& Chae, Y.J. 2012. Management of paradox: A comparative study of managerial practices in Korean and Japanese firms. International Journal of Human Resource Management, 23 (17): 3501-3521.

Yu, Y. 1987. Shi yu zhong guo wen hua (Scholars and Chinese culture). Shanghai: Shanghai Renmin Pub.

Zhang, J., Ahammad, M. F., Tarba, S., Cooper, C. L., Glaister, K. W., \& Wang, J. 2015a. The effect of leadership style on talent retention during Merger and Acquisition integration: evidence from China. The International Journal of Human Resource Management, 26(7): 1021-1050.

Zhang, L., Deng, Y., \& Wang, Q. 2014. An Exploratory Study of Chinese Motives for Building Supervisor-Subordinate Guanxi. Journal of Business Ethics, 124(4): 659675.

Zhang, X.-a., Li, N., \& Harris, T. B. 2015b. Putting non-work ties to work: The case of guanxi in supervisor-subordinate relationships. The Leadership Quarterly, 26(1): 3754. 
Table 1. An overview of informants in the study

\begin{tabular}{|l|l|l|l|l|l|}
\hline & Banking & Construction & Mining & Telecommunication & Aerospace \\
\hline Senior manager & 5 & 1 & 2 & 1 & 1 \\
\hline Middle manager & 7 & 3 & 3 & 2 & 3 \\
\hline
\end{tabular}


Table 2. Ambidexterity in the S-S relationship

\begin{tabular}{|c|c|c|c|c|}
\hline Dimensions & $\begin{array}{c}\text { Relation-based } \\
\text { Guanxi }\end{array}$ & Selective empirical evidence & $\begin{array}{c}\text { Merit-based } \\
\text { Guanxi }\end{array}$ & Selective empirical evidence \\
\hline Loyalty & $\begin{array}{l}\text { To individual } \\
\text { superior }\end{array}$ & $\begin{array}{l}\text { I work hard to make sure that I won't } \\
\text { let my boss down. I'm happy with this } \\
\text { good relationship and therefore I don't } \\
\text { care that I work hard and work } \\
\text { overtime. Because he recognizes my } \\
\text { capability, I must work hard to return } \\
\text { his kindness to me." } \\
\text { When I began my career, the boss } \\
\text { called for young employees to attend } \\
\text { meetings and dialog sessions. After } \\
\text { meetings, everyone needed to write a } \\
\text { report. Afterwards I was transferred to } \\
\text { an operational department, and actually } \\
\text { got promoted. I feel very grateful to the } \\
\text { people who promoted me. Although I } \\
\text { have a very busy schedule now, I still } \\
\text { often visit my old boss during holidays } \\
\text { or traditional festivals. }\end{array}$ & To organization & $\begin{array}{l}\text { I only do things if it can benefit the firm, not the boss. } \\
\text { Normally, the boss would prefer that you do things that make } \\
\text { him look good. The team I am in charge of belongs to his } \\
\text { department. The boss thought our achievement should bear his } \\
\text { label. I disagree with this approach. I think we should do what } \\
\text { is best for the organization. Therefore, conflicts between my } \\
\text { boss and me are inevitable. }\end{array}$ \\
\hline
\end{tabular}


I need to deal with routine monitoring from the level above me carefully, such as reporting and finance. These things need to be done without any mistakes, because they are closely related to my boss's image and reputation. Therefore, if I guide people effectively in our department, handle reporting, finance, and HR well, our boss will be happy.

Your good business skills are a basic but not a critical factor in your success. The most important factor for your success is the Guanxi with your supervisor. Only your emotional intelligence can help you deal with this Guanxi. For example, you should not aim to do something that satisfies yourself but something that satisfies your leader.

If you have a good social relationship, you can walk smoothly, otherwise even if your business ability is extremely good, you still cannot be promoted. Your leadership and working abilities both depend on this. This is because you cannot achieve anything or do anything without the support of more senior people, even if you possess strong leadership capabilities.
At that time I was receiving a good salary working for a Chinese financial institution in Hong Kong, whereas the compensation package on the mainland was not competitive at all. I also got some opportunity to work for foreign banks with a big salary in Shanghai. However, after serious consideration I decided to use what I learned abroad in order to help the development of the Chinese finance industry. I believe what I learned can make a big difference to China. Why should I work for foreign banks? If so, I would have been just a money-making machine for the employers and myself. I should devote my energy and time to helping Chinese organizations.
Independent from superior /Transactional

I do not have any background or family resources that I could use for my professional career. Every step I need to overcome obstacles. Supervisor did not play a key role in my career development. It was not because others put me in the good spot, but my own ability and skillset. What I am concerned with is how our firm is doing, not those relationships with bosses"

As a junior economist, I made two recommendations to my supervisor, the chief economist. He disagreed with my views and thought the market would react differently. He intended to fire me, and put me in a difficult situation. Time proved that I was right, based on my data analysis and my solid research skills. I worked up the courage and I spoke directly with higher chief economist and explained the situation. Very 
Therefore, business ability for a banker is simply a very basic thing, whereas

your human relations within your

department and the bank, and your

social relationships are most important.

Every day, my primary work is to figure out how to deal with complex

Guanxi and how to establish advanced Guanxi with significant people. As for social activities, the boss loves playing chess; me too. The boss also likes

Political skills

/ Satisfaction of

Work priority superior playing tennis. I am a big tennis fan. In

a large hierarchical organization like

ours, the message from the top needs to be transmitted to the bottom. The one

Performance

who can understand the boss's

intention and is able to read between

the lines can be promoted quickly.

Later on I was moved to the bank's head office, with the help of the deputy president. This is because I have established a trust relationship with him. Once you move into society, you find that some people have similar tastes, hobbies, and principles to yours. Then you subconsciously form your own Guanxi network. Although such a team has no boundary, there is a kind of special cultural glue that bonds people together. quickly, they fired my supervisor.

"I don't want to be labelled with Mr. M in the future when I make progress in my career. Had I taken the post, others would say it was due to my secretary position for Mr. M that I could get promoted.... I have to sincerely convey the message that I am not the suitable person. Simply put, I don't want to have the tag of Mr. M for my career."

My supervisors often say that I'm a smart guy with integrity and honesty. I also mentioned to others that my career advancement was never based on connection, such as finding someone, or having special channels. Normally, I wouldn't know I would get promoted beforehand until the HR assignment letter arrived. 
If you don't recognize the politics at the office, you might lose in key

situations. At one time, my supervisor was satisfied with my work and

personality, however there are so many other factors that can influence the job promotion process. Especially, there

were other competitors who were good

at accumulating and using political

skills. In the end, I didn't win the

promotion, although my work

experience and personal integrity

scored high.
If you deliberately act to please the boss, it might not lead to

the expected outcome. For example, if you head toward the

East to accommodate the boss, you may find that the boss

aims for the West. Therefore, it is your performance, work

quality, and integrity that determine your career. Eventually,

the boss will like you because of your performance. 


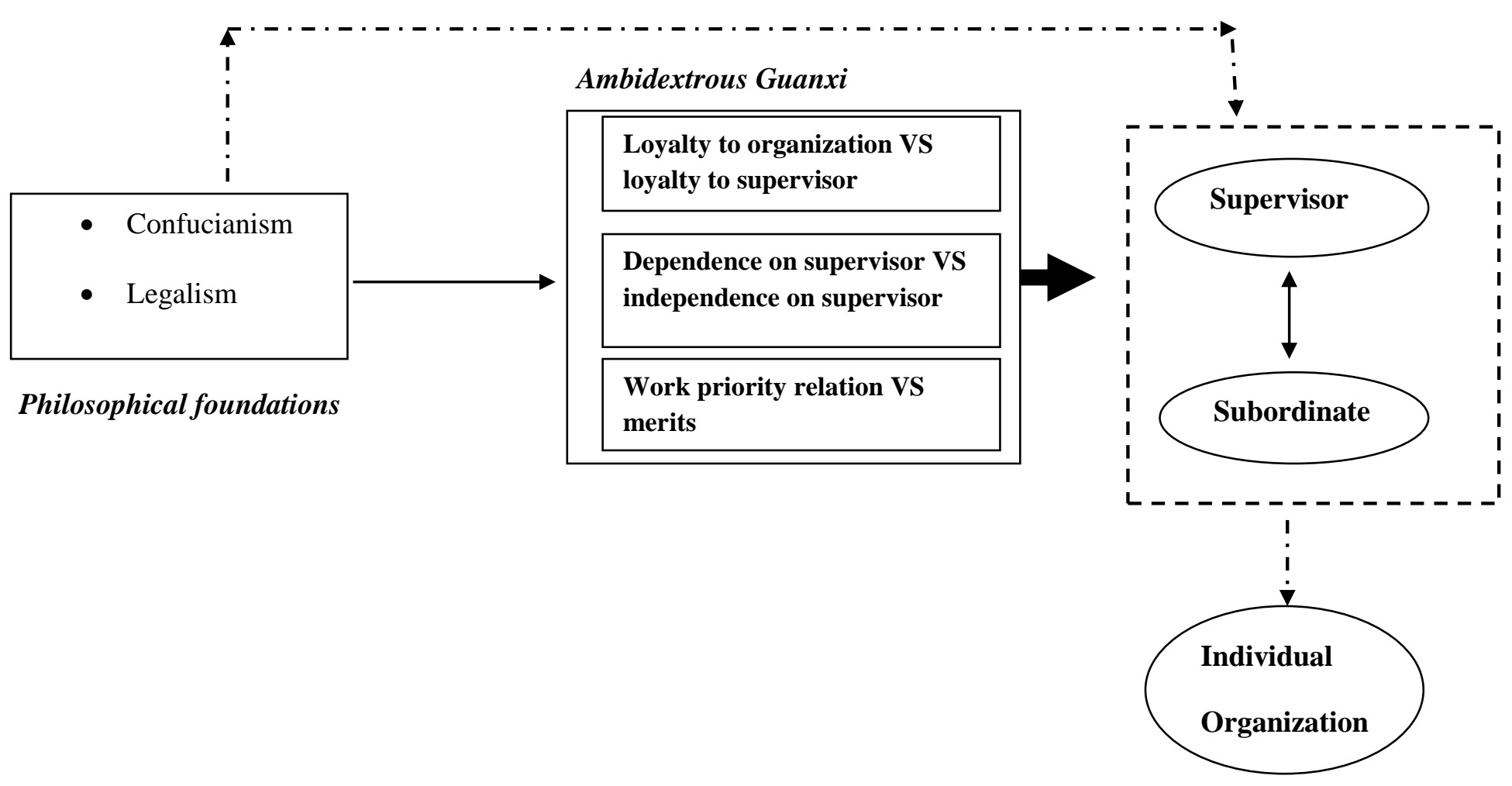

Figure 1. Conceptual framework of the philosophical influences on the supervisor-subordinate relationship 


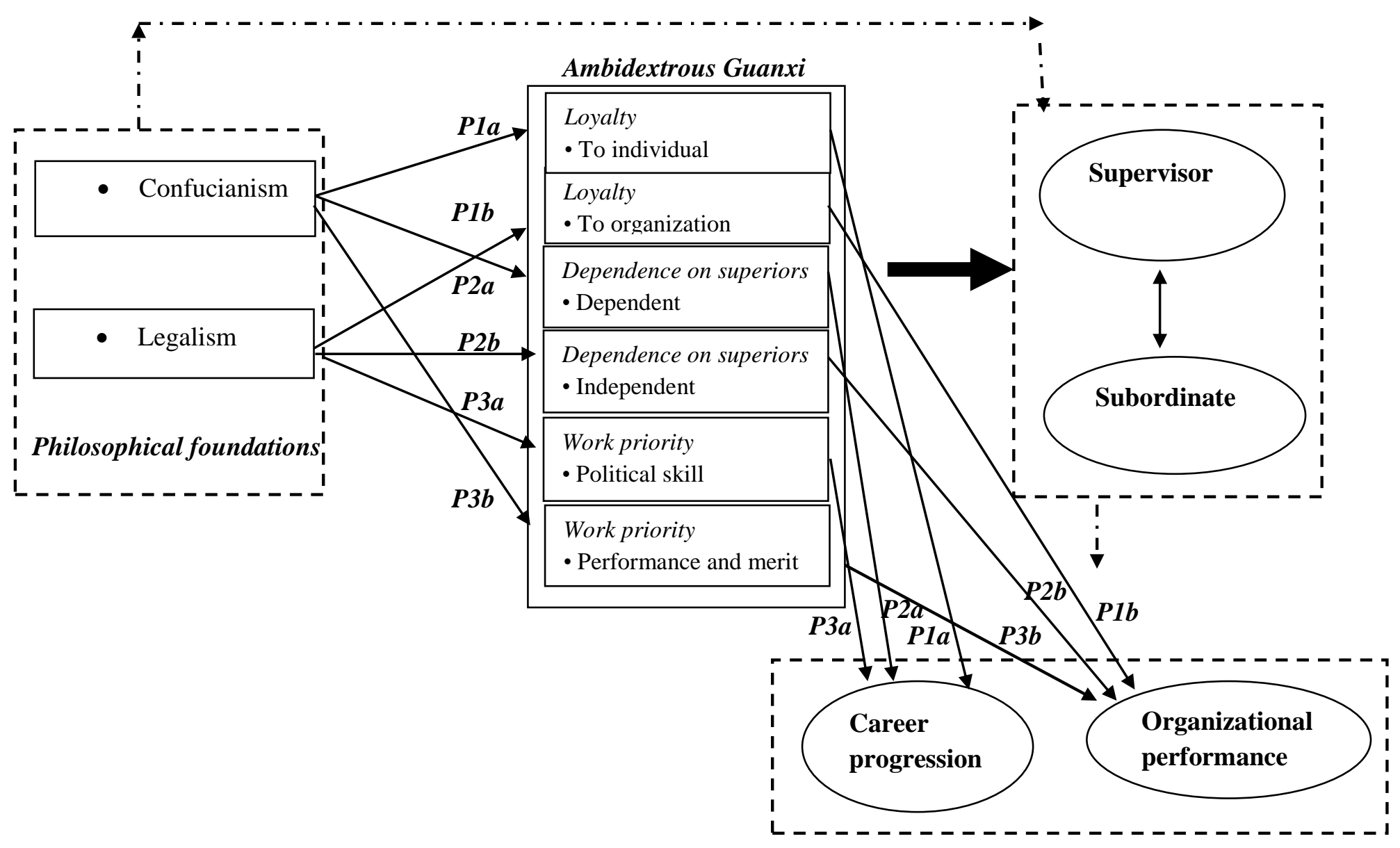

Figure 2. Conceptual framework of ambidextrous Guanxi in the S-S relationship 